\title{
Investigation of probable failure position in helical compression springs used in fuel injection system of diesel engines
}

\author{
Brita Pyttel ${ }^{1}$, K K Ray ${ }^{2}$, Isabell Brunner ${ }^{3}$, Abhishek Tiwari ${ }^{4}$, S. A. Kaoua ${ }^{5}$ \\ ${ }_{1,3}$ (State material testing department, Technical University Darmstadt, Germany) \\ ${ }^{2,4}$ (Metallurgical and Materials Engineering department, Indian Institute of Technology Kharagpur, India) \\ ${ }^{5}$ (Laboratoire de science et de ge nie des mate 'riaux, U.S.T.H.B, BP 32, El Alia Babezzouar 16311, Alger, \\ Algeria)
}

\begin{abstract}
Helical compression springs are used generally in fuel injection system of diesel engines, where it undergoes cyclic loading for more than $10^{8}$ numbers of cycles. In order to predict probable failure positions in helical compression springs, used in fuel injection system, along the length of the spring at inner side, finite element analyses was carried out, using ABAQUS 6.10. The simulation results show an oscillatory behaviour of stresses along the length at inner side. It was confirmed that the oscillation was due to bending involved with compression. It was also revealed that the bending was due to the geometry of springs. Shear stresses along the length of the spring were found to be asymmetrical and with local maxims at starting of each middle coil. The asymmetry was due to the end coil smaller than 360 degrees.
\end{abstract}

Keywords- Helical compression springs, Maximum shear stress, Finite element analysis

\section{Introduction}

Helical compression springs are crucial component of an automobile diesel engine fuel injection system, as it is loaded for more than $10^{8}$ numbers of cycles. To investigate the very high cycle fatigue behaviour of helical compression springs, analyses were done in State Material Testing department of Technical University Darmstadt (TUD), on springs of different materials and geometries ${ }^{[1]}$. In these analyses, it was found that the failure generally occurs at inner side of the wire of a spring but along the length of the spring probable failure position were distributed along the length with no theoretical explanation. Theoretical concepts ${ }^{[2]}$ though explain the stress distribution along the transverse wire, but none of it explains the stress distribution along the length. Moreover, analytical expressions do not take the effect of ground surfaces and varying pitch angle along the length in consideration. Therefore, in order to predict the probable failure positions, a Finite Element (FE) analysis was conducted in the same facility of TUD, using ABAQUS 6.10. The FE analyses were static stress analyses, with geometry transformed from cylindrical coordinates obtained from BOSCH GmbH for springs used in fuel injection system to Cartesian coordinates.

\section{Finite Element Modelling}

Finite element modelling was done using the cylindrical coordinates obtained from the spring manufacturer. These coordinates were transformed to Cartesian coordinates and exported to ABAQUS 6.10 to form a curve shown in Fig. 1.

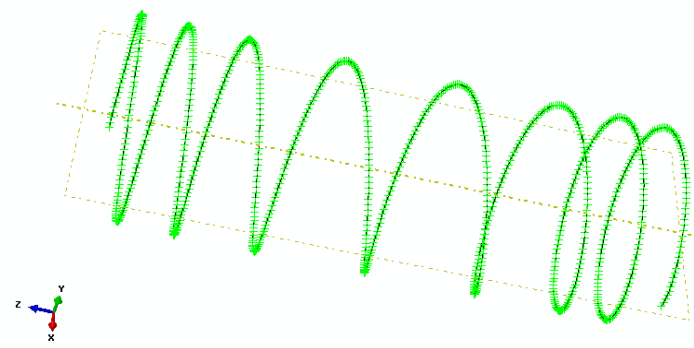

Figure 1. Curve formed by joining the points transferred to ABAQUS in the form of cartesian coordinate data

The different geometries of springs analysed by ABAQUS are shown in Table 1. The Force amplitudes were measured by a hydraulic machine which compresses the spring to a fixed stroke. With the help of force displacement data obtained from the software of this machine, spring rate were measured as the slope of force displacement plot for each spring. The stress correction factor was calculated with the help of Bergstaesser's[3] expression. 
Investigation of probable failure position in helical compression springs used in fuel injection system Table 1.Geometrical parameters and calculated shear stresses of springs used in FE analyses

\begin{tabular}{|l|l|l|l|l|l|l|}
\hline $\begin{array}{l}\text { Code } \\
\text { Name }\end{array}$ & $\begin{array}{l}\text { Spring } \\
\text { rate } \\
\mathbf{( N / m m )}\end{array}$ & $\begin{array}{l}\text { Free } \\
\text { Length } \\
\left.\mathbf{L}_{\mathbf{0}} \mathbf{( m m}\right)\end{array}$ & $\begin{array}{l}\text { Force } \\
\text { amplitude } \\
\square \mathbf{F} \text { (N) }\end{array}$ & $\begin{array}{l}\text { Stress } \\
\text { correction } \\
\text { factor(k, } \\
\text { Bergstraesser) }\end{array}$ & $\begin{array}{l}\text { Mean } \\
\text { coil } \\
\text { diameter } \\
\mathbf{D}_{\mathbf{m}}(\mathbf{m m})\end{array}$ & $\square \square(\mathbf{M P a})$ \\
\hline BS1 & 8.58 & 31.43 & 70.8 & 1.18 & 11.86 & 627 \\
\hline BS2 & 9.47 & 30.76 & 78.8 & 1.19 & 11.6 & 685 \\
\hline BS3 & 9.99 & 30.11 & 83 & 1.19 & 11.34 & 708 \\
\hline BS4 & 10.43 & 29.8 & 87 & 1.19 & 11.07 & 728 \\
\hline BS5 & 11.5 & 29.38 & 96 & 1.2 & 10.87 & 791 \\
\hline BS6 & 12.32 & 28.64 & 101.8 & 1.21 & 10.55 & 819 \\
\hline
\end{tabular}

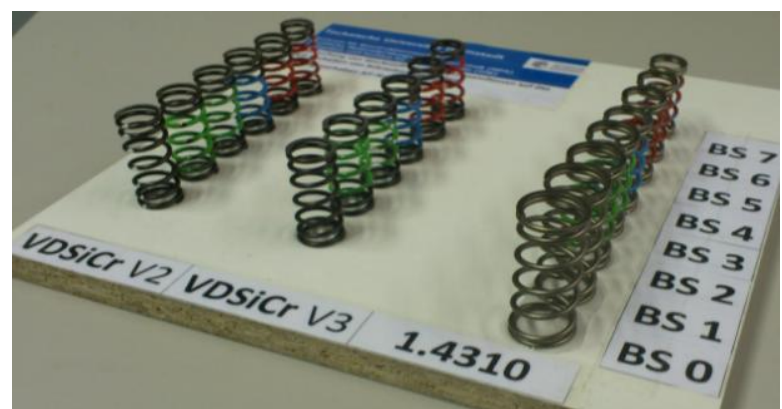

Figure 2.Picture of springs with code names used in FE analyses and material codes

\section{Methodology}

The coordinates of points at the centre of wire of each spring were exported to ABAQUS 6.10 and a circle of radius $0.8 \mathrm{~mm}$ was extruded along the curve. The springs were cut at lower end and upper end at to make the spring ground and to match with the measured length of the spring. A circular slot of $16.5 \mathrm{~mm}$ diameter was designed in a rectangular frame of $20 / 20 \mathrm{~mm}$ cross section. In the spring fatigue testing machine used in TUD, the springs were kept in a frame with a circular slot for each spring to stand, of a diameter of 16.5 $\mathrm{mm}$. This rectangular parallellopipe with circular slot will be referred as frame. Spring was assembled with these frames at upper and lower end of springs and circular slot placed on the ground surface of spring, as shown in Fig. 3.

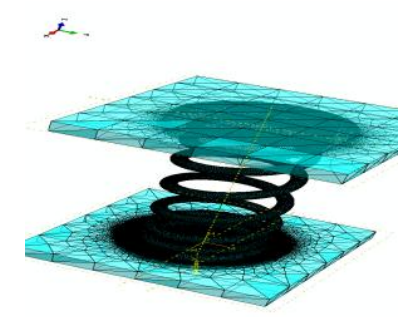

Figure 3. Assembly of FE model in ABAQUS after meshing by TET-C3D10 type of elements

\subsection{Fatigue loading}

The cyclic loading process details of springs is taken from the experiment carried out in TUD by Pyttel et al [1], and is shown in Fig. 4. The springs were loaded to a mean stress by compressing it to attain a length of $20.2 \mathrm{~mm}$ and then a tension and compression cycle was given to springs so that springs have amplitude of stroke of $8.39 \mathrm{~mm}$.
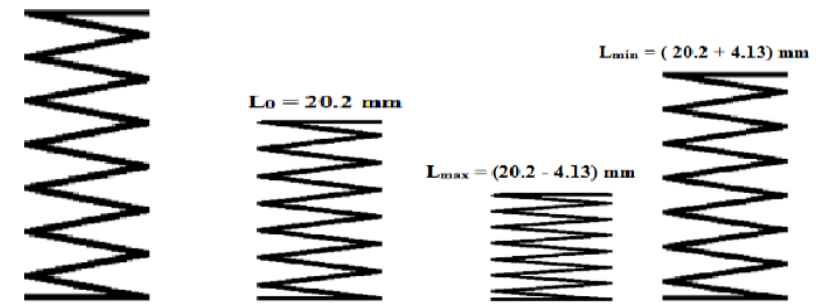

Figure 4. Loading cycle given to spring in spring fatigue testing machine[1] 


\subsection{Meshing and shear stress calculation}

The element types found suitable for uniform meshing for whole assembly were TET-C3D10 and TET-

C3D4 (Tetragonal elements with quadratic shape function and linear shape function) and after comparison, TET-C3D10 were found to be closer to the values obtained analytically. Therefore, most of the analyses were carried out using C3D10 type elements. The parameter which was extracted from the output of FE analyses was TRESCA. TRESCA by its definition can be represented as:

$$
\sigma_{\text {TRESCA }}=\left|\left(\sigma_{1}-\sigma_{3}\right)\right|
$$

where $\sigma_{1}=$ Maximum principle stress

$\sigma_{3}=$ Minimum principle stress.

It is well known that maximum shear stress is half of the value shown in equation 1, in magnitude.

$$
\text { Therefore, } \quad \tau_{\mathrm{Max}}=\sigma_{\mathrm{TRESCA}} / 2
$$

The Tresca values for a displacement of $\mathrm{L}_{\max }$ and $\mathrm{L}_{\min }$ were extracted from output of $\mathrm{FE}$ analyses, where

$$
\begin{aligned}
& \mathrm{L}_{\max }=\mathrm{L}_{0}-20.2-8.39 / 2 \\
& \mathrm{~L}_{\text {min }}=\mathrm{L}_{0}-20.2+8.39 / 2
\end{aligned}
$$

$\mathrm{L}_{0}=$ Free length of spring

Therefore, amplitude of maximum shear stress can be given as

$$
\Delta \tau_{\max }=\tau_{\max }-\tau_{\min }=\left\{\left[\sigma_{\text {TRESCA }} / 2\right] \text { at } \mathrm{L}_{\max }\right\}-\left\{\left[\sigma_{\text {TRESCA }} / 2\right] \text { at } \mathrm{L}_{\min }\right\}
$$

\section{Results And Discussions}

\subsection{Stresses along wire diameter}

The maximum shear stress distribution along horizontal wire from inner to outer side has been explained by Wahl ${ }^{[2]}$, which is shown in Fig. 5 and can be given as

$$
\Delta \tau_{\max }=\frac{32 x \Delta F r^{2}}{\pi d^{4}\left(r-\frac{d^{2}}{16 r}-x\right)}
$$

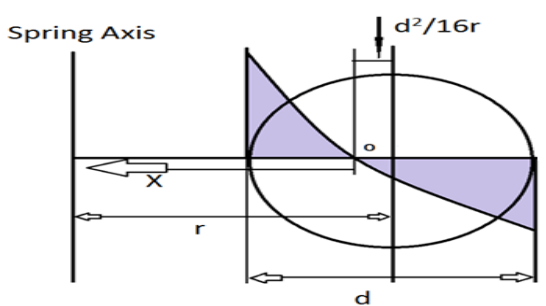

Figure 5.Shear stress distribution along the horizontal wire diameter in a spring [2]

Where $r=$ mean coil radius

$\mathrm{X}=\mathrm{x}$ axis positive towards inner side of wire, and starts from shifted origin.

The distribution plot in Fig. 5 shows that the zero stress point lies at the inner side of the spring. The distribution of amplitude of maximum shear stress obtained from FE analyses, for BS5 spring is shown in Fig. 6.

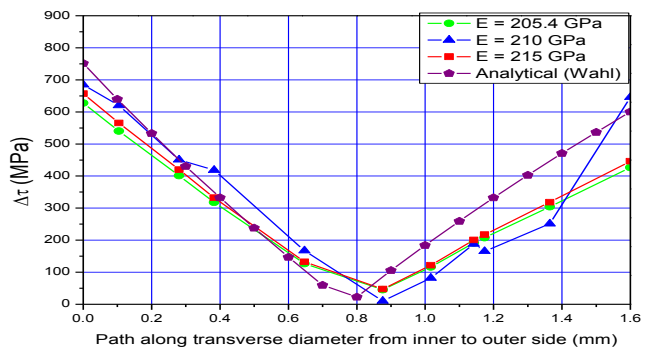

Figure $6 . \Delta \tau_{\max }$ distribution along the wire diameter from inner to outer side of wire of BS-5 spring, for varying young modulus (E) with plot of analytical values obtained from Wahl's equation (Eqn. 6) 
From Figure 6 it is evident that the zero stress point is at outer side of the wire unlike explained by Wahl. The reason for this behaviour can be explained with further demonstrating the equation derived by Wahl. From equation $x$, putting $x=d / 2-d^{2} / 16 r$, maximum shear stress at inner side can be obtained, and which is given in equation 6 :

$$
\Delta \tau_{\max }=\frac{16 \Delta F r}{\pi d^{3}} \cdot\left(\frac{4 w-1}{4 w-4}\right)
$$

Whereas, the expression is not complete and a part of shear stress due to applied axial force has to be added which has also been explained by Wahl.

The total expression for corrected shear stress can be given as:

$$
\Delta \tau_{\max }=\frac{16 \Delta F r}{\pi d^{3}} \cdot\left(\frac{4 w-1}{4 w-4}+\frac{4 w-1}{4 w-4}+\frac{0.615}{w}\right)
$$

The last term in bracket of equation 8 , which comes due to applied axial load, has not been considered in the expression shown in equation 6 and also Figure 6.

In Figure 6, it is evident that the stress is higher at inner side and lower at outer side of the wire and therefore, the zero stress point should be towards inner side to equalize the energy at both side, whereas, if the effect of torsion due to applied load " $\mathrm{F}$ " is also considered then it becomes very easy to understand that torsion is smaller at inner side and higher at outer side as the distance of inner side of wire from spring axis is smaller than the outer side and therefore if torsional energy is included, the zero stress point should be at outer side of the wire centre as estimated by FE analyses.

\subsection{Stress distribution along the length of the spring at inner side}

By making a path at the locus of points at inner side of the wire of spring along the length, stresses were extracted. The distribution of amplitude of maximum shear stress along the path is shown in Figure 7.

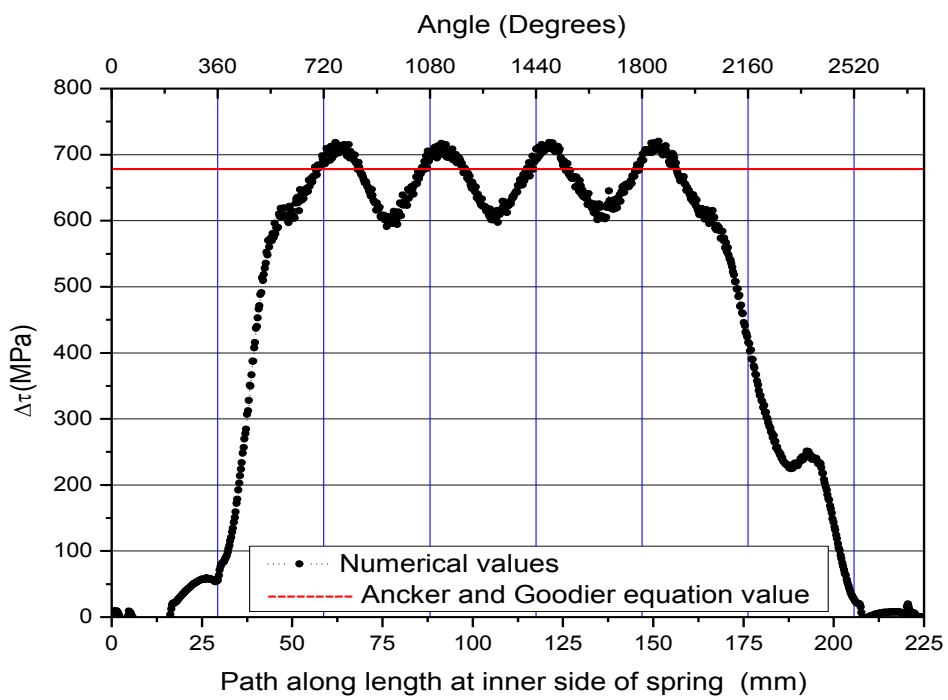

Figure 7. $\Delta \tau_{\max }$ distribution along the length of BS-5 spring at inner side, with red line representing the values calculated by Ancker and Goodier's equation [4]

In the Figure 7, the red line represents the values obtained by Ancker and Goodier[4] equation which includes the effect of small pitch angle. It can be observed from the same figure that

1. The stresses are oscillatory in the middle part of the distribution curve

2. The stress behaviour is asymmetrical at lower and upper end coil

3. The stresses do not match with the analytical result

Maximum shear stress amplitude distribution estimated by FE analyses was found to be oscillating because of bending involved with axial loading due to geometry effect. In Figure 8, it is shown that an ideal spring should stand straight whereas, the spring used for this investigation had a tilt. 


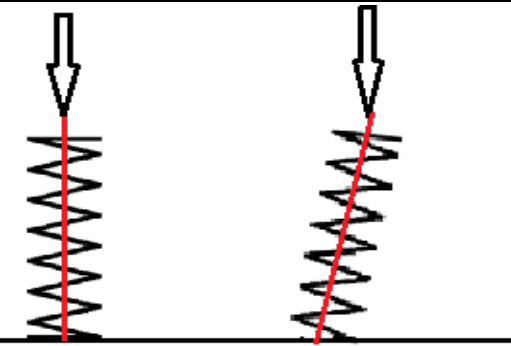

Figure 8. Ideal spring (at left) and schematic of springs used for FE analyses (at right) with a tilt due to geometry

This tilt in the spring caused bending of spring in a plane paralle to spring axis and also on the $r-\square$ plane as shown in Figure 9. This rotation on $\mathrm{r}-\square$ plane by an angle $\square$, causes terms of trignometrical functions in the transformation matrix of displacement from $\mathrm{X}_{1}{ }_{1}-\mathrm{X}_{2}{ }_{2}$ coordinate system to $\mathrm{X}_{1}-\mathrm{X}_{2}$ system. The rotation on plane parallel to spring axis also causes a similar effect and in the end there are two transformation matrices involved. The transformation matrix caused by rotation on $r-\square$ plane is expressed by equation 9 .

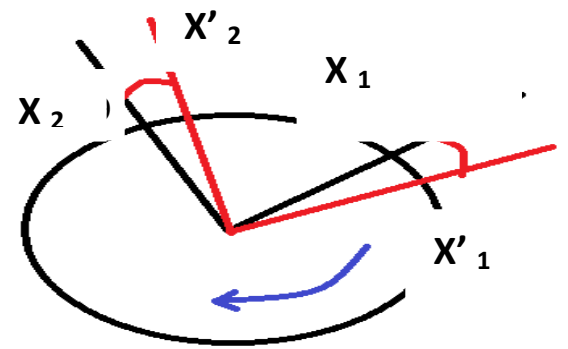

Figure 9.Schematic of rotation on $r-\square$ plane while loading in a spring, with $X_{2}$ axis along spring axis

$$
\mathrm{T}=\left[\begin{array}{ccc}
1 & 0 & 0 \\
0 & \cos \theta & -\sin \theta \\
0 & \sin \theta & \cos \theta
\end{array}\right] \quad \mathbf{r}-\boldsymbol{\theta} \text { Plane }
$$

Due to periodic sine and cosine functions involved in the calculation of displacement and in stresses the shear stress distribution becomes periodic in nature. At the end coils due to friction involved and ground surfaces of springs, the rotation is less whereas at the lower end the coil of the spring in not completely $360^{\circ}$, and thus the hump in Fig. 7 in the lower end coil at right side, is asymmetrical with the upper coil. This can be confirmed by flipping the spring in the FE-analyses.

The oscillatory behaviour of shear stresses along length of a spring should be different for closed end coil springs which have smaller pitch for end coils than that for open end coil springs. Therefore, an analysis for a similar spring (BS-1) with closed ground end coil was conducted and it was found that the amplitude of oscillations was lower than that for open end coil. The behaviour of stresses is shown in Fig. 10. The closed end coil springs has lower tilt and therefore it should have less amount of rotation while loading which causes the decrease in amplitude of oscillation in shear stresses estimated by FE analyses.

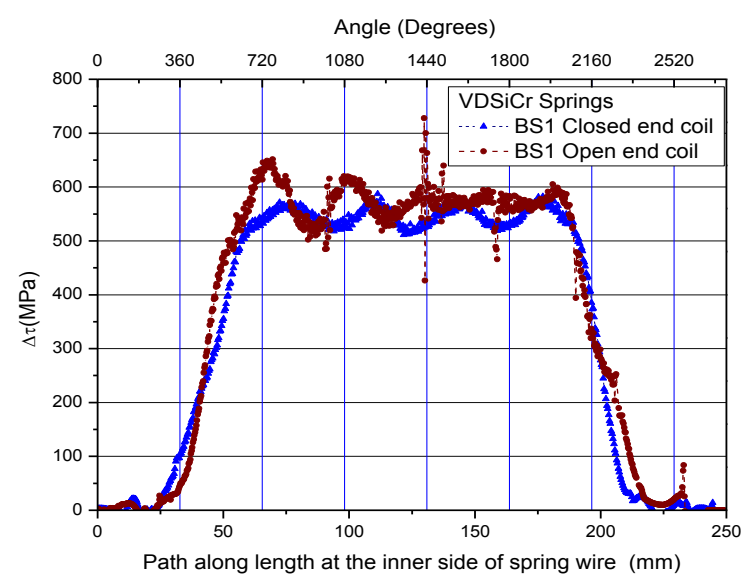

Figure $10 . \Delta \tau_{\max }$ distribution along the length of BS-1 open and closed end coil springs at inner side 


\subsection{Probable Failure positions}

The maximum shear stress points estimated by FE-analyses are at the staring of each coil except end coils and lies in n. 2 to n. 5 number of coils, where number of coils are defined as:

Coil number $=$ Angle in degrees $/ 360$

$\mathrm{n}=$ number of coil

\section{Conclusions}

The probable failure locations were found to be at the starting of each coil as shown in Fig. 7. The oscillatory behaviour of stresses was also responsible for causing rotational movement of springs in slots, observed in experimental analyses. The failure locations matched with considerable amount of failures occurred in experiment. The FE-analyses need to be modified further for cyclic analysis and failure analyses with a modified sub-routine to be used with ABAQUS.

\section{ACKNOWLEDGEMENT}

This work was supported and financed by TUD state materials testing department (MPA/iFW) and BOSCH GmbH, and therefore their curtsey is acknowledged for its success.

\section{Refernces}

[1] Kaiser B., Pyttel B., Berger C., VHCF-behavior of helical compression springs made of different materials, International Journal of Fatigue, 33, 2011, 23-32

[2] A. M. Wahl, Mechanical Springs( Macgraw Hill Book company. Inc., Second Edition, New York, 1963)

[3] Bergstraesser, M., Die Beanspruchung zylindrischer Schraubenfedern, ZVDI, 77, 1933, 198

[4] Ancker C.J., Goodier, J., N., Theory of pitch and curvature correction for the Helical Springs-1, Journal of Applied Mechanics, 1958,471 